\title{
Prevalence and risk factors for soil-transmitted helminth infection in mothers and their infants in Butajira, Ethiopia: a population based study
}

Yeshambel Belyhun ${ }^{1}$ Girmay Medhin ${ }^{1}$, Alemayehu Amberbir ${ }^{2,3^{*}}$, Berhanu Erko ${ }^{1}$, Charlotte Hanlon ${ }^{4}$, Atalay Alem , Andrea Venn ${ }^{3}$, John Britton ${ }^{3}$, Gail Davey ${ }^{2}$

\begin{abstract}
Background: Soil-transmitted helminths (STHs) are widespread in underdeveloped countries. In Ethiopia, the prevalence and distribution of helminth infection varies by place and with age. We therefore investigated the prevalence of and risk factors for STH infection in mothers and their one year-old children living in Butajira town and surrounding rural areas in southern Ethiopia.
\end{abstract}

Methods: In 2005-2006, 1065 pregnant women were recruited in their third trimester of pregnancy. In 2006-2007, when children reached their first birthdays, data on the infants and their mothers were collected, including stool samples for qualitative STH analysis. Questionnaire data on various demographic, housing and lifestyle variables were available. Logistic regression analysis was employed to determine the independent risk factors for STH infection in the mothers and children.

Results: 908 mothers and 905 infants provided complete data for analysis. Prevalence of any STH infection was $43.5 \%$ (95\% confidence interval $(\mathrm{Cl}) 40.2-46.8 \%)$ in mothers and $4.9 \%(95 \% \mathrm{Cl} 3.6-6.5 \%)$ in children. In the fully adjusted regression model, infrequent use of soap by the mother was associated with increased risk (odds ratio (OR) 1.40, 95\% Cl 1.04-1.88, and 1.66, 95\% Cl 0.92-2.99, for use at least once a week and less frequent than once a week respectively, relative to daily use; $\mathrm{p}$ for trend $=0.018)$, and urban place of residence $(\mathrm{OR} 0.45,95 \% \mathrm{Cl} 0.28$ $0.73, p=0.001$ ) was associated with reduced risk of maternal STH infection. The only factor associated with STH infection in infants was household source of water, with the greatest risk in those using piped water inside the compound (OR 0.09, 95\% Cl 0.02-0.38 for river water, 0.20, 95\% Cl 0.56-0.69 for either well or stream water and $0.21,95 \% \mathrm{Cl} 0.09-0.51$ for piped water outside compared with piped water inside the compound, overall $p=0.002$ )

Conclusion: In this rural Ethiopian community with a relatively high prevalence of STH infection, we found a reduced risk of infection in relation to maternal hygiene and urban living. Daily use of soap and a safe supply of water are likely to reduce the risk of STH infection.

\section{Background}

Soil-transmitted helminths (STHs) are a group of nematodes that infect more than a billion people worldwide [1]. Of particular public health importance are Ascaris lumbricoides, Trichuris trichiura and hookworms [1,2]. Strongyloides stercoralis is also a STH [3], although detailed information on the prevalence is lacking. In Ethiopia the prevalence of hookworm is estimated to be $16 \%$ and the prevalences of $A$. lumbricoides and $T$.

\footnotetext{
* Correspondence: alamwo1@yahoo.com

${ }^{2}$ School of Public Health, Addis Ababa University, Addis Ababa, Ethiopia
}

trichiura are $37 \%$ and $30 \%$ respectively [4]. STH infections have not been targeted for control in Ethiopia [4], though mass de-worming as a component of the Enhanced Outreach Strategy (EOS) targeting under five children started in 2004 [5].

In developing countries, where control measures are often difficult to implement, STHs remain a significant health problem [6,7]. It is estimated that between a quarter and a third of pregnant women in sub-Saharan Africa are infected with hookworm and are at risk of preventable hookworm-related anemia [8]. Many 
children living in endemic areas are infected continuously from soon after birth and often experience chronic ill health [1,9]. Infections with STHs may have important health consequences during this developmental stage, affecting child health and development, slowing down growth and reducing adults productivity and work capacity $[1,6,7,9]$. These helminth infections may also elicit potent immune responses through effects on the immune system $[1,10]$.

Intervention against STH infection is based on regular anti-helminthic treatment, improved water supply, sanitation and health education [11]. Low-cost, high-coverage delivery of anti-helminthic treatment has been achieved in some settings [12], but improving sanitation is more complex. In Ethiopia, for example, levels of access to improved sanitation in rural areas are very low (5.4\%) [13], making evaluation of other components of intervention important. In this study, we present data from an area in which intermittent mass de-worming has been carried out [14], but where levels of sanitation are still rudimentary. We present data on prevalence of STH infection among mothers and one-year old children in a rural area of Ethiopia using a populationbased birth cohort to define the prevalence of STH infection and identify factors amenable to intervention.

\section{Methods}

\section{Study area and population}

The study site was the Butajira area, which is located in Gurage zone, Southern Ethiopia. The capital Butajira lies at a distance of $130 \mathrm{Km}$ from the capital, Addis Ababa. The area is predominately rural and most residents live in villages as agriculturists growing coffee, maize, teff (Eragrostos tef), pepper, the stimulant khat (Catha edulis forskal) and enset (false banana) [14]. The total population of the study area is approximately 250,000, with a diverse multi-ethnic group; the Gurages (Meskan, Mareko and Silti) form the majority [14]. Deworming started in the study area in 2006 as part of the Enhanced Outreach Strategy (EOS) [15]. Antihelminthics have been given regularly in ten successive rounds in under five children, covering 41 administrative units of Butajira district and its surroundings [15].

\section{Study design and procedures}

The Butajira Rural Health Project (BRHP), a Demographic Surveillance Site (DSS) covering nine rural and one urban administrative area, was established in 1987 [14]. The DSS population currently is around 60,000 with more than 13,000 women of reproductive age. Between July 2005 and February 2006 all pregnant women in their third trimester and aged 15-49 years were identified from the BRHP and a birth cohort established, details of which have been reported elsewhere
[16]. Of the 1234 eligible women identified, 1065 were recruited and these women gave birth to 1006 live singleton babies (Fig 1). Those mother-child pairs still living in the area and alive $(n=932)$ were followed up and data were collected between July 2006 and June 2007, at the time of the child's first birthday.

\section{Data collection}

After written consent was obtained from the mothers of participating children, stool samples were collected from both the mother and child. Samples were collected by data collectors known to the mothers and children since the initiation of the birth cohort. The stool samples were placed in labeled plastic tubes containing $10 \%$ formalin and transported for analysis to the Aklilu Lemma Institute of Pathobiology, Addis Ababa University. Samples were then examined qualitatively using the formol-ether concentration method [17]. Information on demographic and lifestyle factors was collected by interviewer-administered questionnaire during initial recruitment of the mother during pregnancy and at the first year follow up.

\section{Data management and analysis}

Data on parasites were entered into Excel and manually checked for error against the hard copies. Questionnaire data were double-entered into EpiData

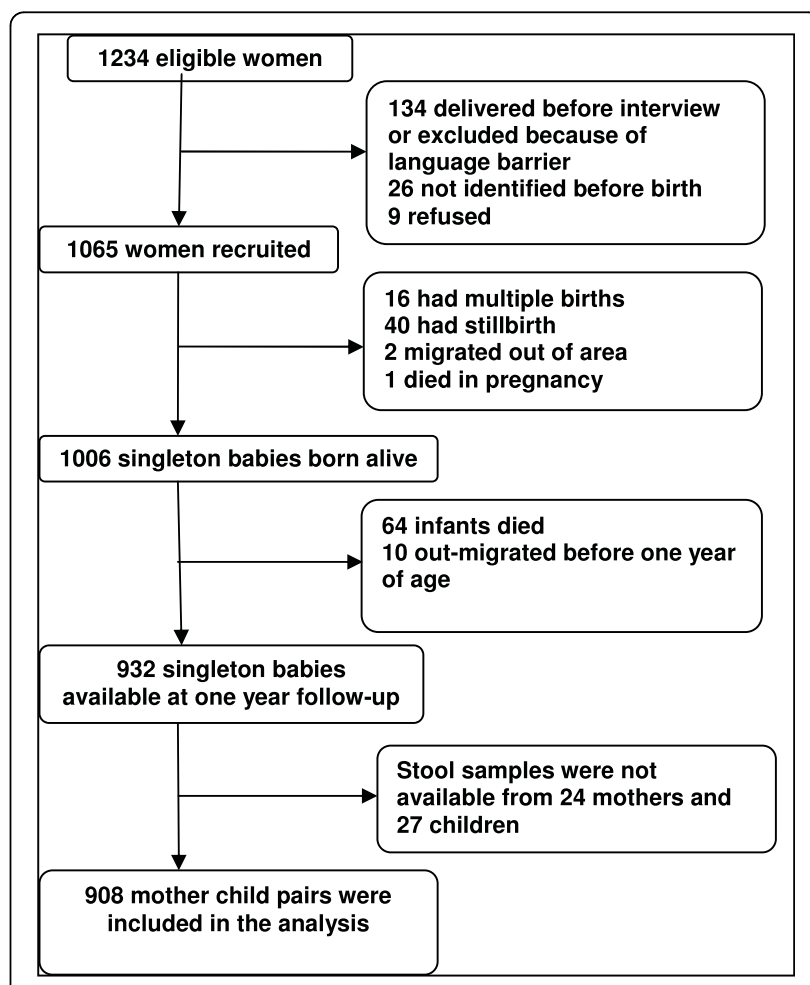

Figure 1 Study cohort. 
version 3. Analysis was performed using SPSS version 12.0.1 (SPSS Inc. Chicago, IL). The dependent variables were any STH infection in the mother and any STH infection in the child (where STH infection is taken to mean infection with any of A. lumbricoides, T. trichiura, hookworm or S. stercoralis). Potential risk factors explored were demographic factors (gender, mother's age, urban/rural place of residence and ethnicity), markers of social advantage (education, occupation, home ownership and TV/radio ownership) and factors associated with housing and lifestyle (roof type, type of toilet, water source, animals in the home, place of cooking, soap use, and waste disposal method). Initially the univariate association between each exposure and the presence of infection was assessed using the Chi-squared test and odds ratios were computed as measures of association. To determine the independent risk factors for infection, logistic regression analysis was employed. Variables were manually added and removed from the model until only those that significantly improved the model remained. Urban/rural place of residence and gender (child model only) and additionally age of the mother (maternal model only) were treated as a priori confounders and retained in the model regardless of significance.

\section{Ethical consideration}

Approval for this study was granted by the Ethics Committee of the Aklilu Lemma Institute of Pathobiology, Addis Ababa University. All mothers and children with STH infections were treated with anti-helminthics based on the national protocol.

\section{Results}

\section{Description of the study subjects}

Nine hundred thirty two child-mother pairs were followed up at one year, and 908 (97.4\%) of the mothers

\section{Table 1 Prevalence of soil-transmitted helminth infections in mothers and their infants in the Butajira birth cohort, Ethiopia, 2007}

\begin{tabular}{lrr}
\hline Soil-transmitted helminths & $\begin{array}{r}\text { Children (N = 905) } \\
\text { No (\%) }\end{array}$ & $\begin{array}{r}\text { Mothers (N = 908) } \\
\text { No (\%) }\end{array}$ \\
\hline Hookworms & $21(2.3)$ & $328(36.1)$ \\
Ascaris lumbricoides & $13(1.5)$ & $80(8.8)$ \\
Trichuris trichiura & $4(0.4)$ & $30(3.3)$ \\
$\begin{array}{l}\text { Strongyloides stercoralis } \\
\text { Any soil-transmitted }\end{array}$ helminth infection & $10(1.1)$ & $29(3.2)$ \\
$\begin{array}{l}\text { Prevalence of single infection } \\
\text { Prevalence of double }\end{array}$ & $44(4.9)$ & $395(43.5)$ \\
infection & $40(4.4)$ & $329(36.2)$ \\
Prevalence of triple infection & $4(0.4)$ & $60(6.6)$ \\
\hline
\end{tabular}

$\mathrm{N}=$ total number of study participants and 905 (97.1\%) of their infants provided adequate stool samples and were included in the analysis (Fig 1). The majority were from rural areas $(87 \%)$ and there were roughly equal numbers of male $(460 ; 50.7 \%)$ and female (448; 49.3\%) infants. The age range of interviewed mothers was 15 to 44 years (mean, standard deviation [SD] 26.8 [6.3] years), with almost one third (38.7\%) aged under 25.

\section{Prevalence of soil-transmitted helminths}

Four species of soil-transmitted helminths (STHs) were identified in the stool samples, with the overall prevalence of any STH infection being 43.5\% (95\% confidence interval (CI) 40.2-46.8\%) in mothers, and $4.9 \%$ (95\%CI 3.6-6.5\%) in children, respectively (Table 1). Hookworm was the predominant intestinal helminth infection, detected in $36.1 \%$ of mothers and in $2.3 \%$ of children, and $A$. lumbricoides was the second most frequently detected intestinal parasite with prevalence of $8.8 \%$ in mothers and $1.5 \%$ in children (Table 1 ). About one third (36.2\%) of mothers and $4.4 \%$ of children had a single infection, while $6.6 \%$ of mothers and $0.4 \%$ of children had double infections, $0.7 \%$ of mothers had triple infections (Table 1).

\section{Univariate risk factor analysis for STH infection in mothers}

The distributions of the demographic and lifestyle factors of the subjects are shown in Tables 2 and 3. In univariate analyses, significant positive associations were seen between presence of any STH in the mother and living in a house with a thatched roof (Odds Ratio (OR) 1.62; 95\% CI 1.18-2.24, $\mathrm{p}=0.003$ ), home ownership (OR $1.67,95 \%$ CI 1.04-2.68, $\mathrm{p}=0.033$ ), cooking inside (OR 1.68; 95\% CI 1.18-2.37, $\mathrm{p}=0.003$ ) and for disposing waste in open field relative to burying or burning (overall $\mathrm{p}=0.013$, OR 1.66; 95\% CI 1.23-2.46). In addition, frequency of soap use was significantly associated with maternal infection with increased risk seen for infrequent soap users compared to daily use (overall $\mathrm{p}=$ 0.008 , OR 1.51, 95\% CI 1.14-2.01). A significant negative association was found in relation to urban living (OR 0.48 ; $95 \%$ CI $0.32-0.73, \mathrm{p}=0.001$ ), whereas the association with education level was only of borderline significance $(\mathrm{p}$ for trend $=0.051$ OR $0.71 ; 95 \%$ CI $0.51-1.00$ ) (Tables 2 and 3 ).

\section{Univariate risk factor analysis for STH infection in children} Significant univariate associations were identified with cooking site (OR 0.43 ; 95\% CI $0.23-0.83$ for inside relative to outside, $\mathrm{p}=0.012$ ), living in a house with a thatched roof (OR 0.51; 95\% CI 0.27-0.96, $\mathrm{p}=0.037$ ) and with household source of water (overall $p<0.001$ ) such that the greatest prevalence of infection was 
Table 2 Univariate analysis of socio-demographic characteristics and their association with soil-transmitted helminths in the birth cohort, Butajira Ethiopia, 2007

\begin{tabular}{|c|c|c|c|c|c|c|c|}
\hline \multirow[t]{2}{*}{ Demographic variables } & \multirow[t]{2}{*}{$\mathrm{N}(\%)$} & \multicolumn{3}{|c|}{ Soil-transmitted helminths in the mother $(\mathrm{N}=908)$} & \multicolumn{3}{|c|}{ Soil-transmitted helminths in the child $(\mathrm{N}=905)$} \\
\hline & & $n(\%)$ & Crude OR $(95 \% \mathrm{Cl})$ & P-value & $n(\%)$ & Crude OR $(95 \% \mathrm{Cl})$ & P-value \\
\hline Male gender & $460(50.7)$ & - & - & - & $18(3.9)$ & $0.66(0.36,1.23)$ & 0.190 \\
\hline Urban residence & $118(13.0)$ & $37(31.4)$ & $0.48(0.32,0.73)$ & 0.001 & $10(8.6)$ & $2.07(1.00,4.32)$ & 0.052 \\
\hline Mother's Age & & & & 0.949 & & & 0.442 \\
\hline $15-24$ & $351(38.7)$ & $155(44.2)$ & 1 & $0.759^{\$}$ & $21(6.0)$ & 1 & $0.224^{\$}$ \\
\hline $25-34$ & $424(46.7)$ & $183(43.2)$ & $0.96(0.72,1.28)$ & & $18(4.3)$ & $0.70(0.37,1.33)$ & \\
\hline $35-44$ & $133(14.7)$ & $57(42.9)$ & $0.95(0.63,1.42)$ & & $5(3.8)$ & $0.61(0.23,1.66)$ & \\
\hline Ethnicity & & & & 0.280 & & & 0.550 \\
\hline Meskan & $429(47.3)$ & $183(42.7)$ & 1 & & $21(4.9)$ & 1 & \\
\hline Mareko & $118(13.0)$ & $57(48.3)$ & $1.26(0.83,1.89)$ & & $8(6.8)$ & $1.41(0.61,3.27)$ & \\
\hline Silti & $211(23.2)$ & $98(46.5)$ & $1.17(0.84,1.62)$ & & $7(3.3)$ & $0.67(0.28,1.60)$ & \\
\hline Others* & $150(16.5)$ & $57(38.0)$ & $0.82(0.56,1.21)$ & & $8(5.4)$ & $1.10(0.48,2.54)$ & \\
\hline Mother's Education & & & & 0.138 & & & 0.124 \\
\hline No education & $639(70.2)$ & $290(45.4)$ & 1 & $0.051^{\$}$ & $32(5.0)$ & 1 & $0.830^{\$}$ \\
\hline Read write $e^{£}$ & $86(9.5)$ & $37(43.0)$ & $0.91(0.58,1.43)$ & & $1(1.2)$ & $0.22(0.03,1.65)$ & \\
\hline Formal education & $183(20.2)$ & $68(37.2)$ & $0.71(0.51,1.00)$ & & $11(6.0)$ & $1.22(0.60,2.46)$ & \\
\hline Mother's Occupation & & & & 0.428 & & & 0.700 \\
\hline House wife & $762(83.9)$ & $338(44.4)$ & 1 & & $38(5.0)$ & 1 & \\
\hline Trade related & $104(11.5)$ & $42(40.4)$ & $0.85(0.56,1.29)$ & & $5(4.9)$ & $0.97(0.37,2.52)$ & \\
\hline Others ${ }^{\circ}$ & $42(4.6)$ & $15(35.7)$ & $0.70(0.36,1.33)$ & & $1(2.4)$ & $0.46(0.06,3.46)$ & \\
\hline Home ownership & $822(90.5)$ & $367(44.7)$ & $1.67(1.04,2.68)$ & 0.033 & $37(4.5)$ & $0.53(0.23,1.24)$ & 0.143 \\
\hline TV/Radio ownership & $466(51.4)$ & $197(42.3)$ & $0.91(0.70,1.18)$ & 0.467 & $27(5.8)$ & $1.52(0.82,2.84)$ & 0.184 \\
\hline
\end{tabular}

* Sodo, Dobi, Oromo, Amhara,

† Farm related, profession related, trade related and daily laborer, ${ }^{\$} \mathrm{p}$ for trend

${ }^{\mathrm{E}}$ read and write but have no formal education

$\mathrm{N}=$ total number of study participants, $\mathrm{n}=$ number of outcome for each exposure

amongst those getting their water from a pipe inside the housing compound (18.5\%), and the lowest in those using a river (3.9\%) (Table 3). Being an urban resident was associated with increased risk of infection in the child (OR 2.07; 95\% CI 1.00-4.32), but this was of borderline statistical significance $(\mathrm{p}=0.052)$.

\section{Risk factors independently associated with STH in mothers}

The independent predictors of maternal infection identified from multivariate analysis are shown in Table 4. Soap use (adjusted OR $=1.40 ; 95 \%$ CI 1.04-1.88 for infrequent users compared with daily users, $\mathrm{p}$ for trend $=0.018$ ) and urban living (adjusted OR $=0.45 ; 95 \% \mathrm{CI}$ $0.28-0.73, \mathrm{p}=0.001)$, remained significant factors.

\section{Risk factors independently associated with STH in children}

In multivariate analysis, after controlling for urban/rural residence and gender, the only significant predictor of infection in children was household source of water ( $p$ $=0.001$ ) with the greatest risk of infection seen for those using piped water inside the compound (Table 4).

\section{Discussion}

This study is the first, to our knowledge, to explore the prevalence of and risk factors for STH infection in an infant population in Ethiopia. The study found a high prevalence of hookworm infection among mothers, which exceeded the national average. However, the prevalence was generally low in children. The study indentified key environmental factors linked with STH infection which are amenable for intervention. Frequency of soap use and urban living were found to be predictors of maternal helminth infection while availability of piped water in the compound was independently associated with increased risk of infant helminth infection.

The findings of this study provide some evidence for environmental and public health measures to counter STH infection; yet they must be interpreted in the light of certain limitations. We lacked the power to identify risks weakly associated with infant infection in this cohort. Moreover, information on potential confounders was based on mothers' self-report, which may have led to information bias. Quantitative egg estimation to measure the intensity of infections using Kato-Katz 
Table 3 Univariate analysis of potential risk factors of soil-transmitted helminths in mother and their infants in the Butajira birth cohort, Ethiopia, 2007

\begin{tabular}{|c|c|c|c|c|c|c|c|}
\hline \multirow[t]{2}{*}{ Risk factor } & \multirow[b]{2}{*}{$N(\%)$} & \multicolumn{3}{|c|}{$\begin{array}{l}\text { Soil-transmitted helminths in the mother } \\
\qquad(\mathrm{N}=908)\end{array}$} & \multicolumn{3}{|c|}{$\begin{array}{l}\text { Soil-transmitted helminths in the child } \\
\qquad(\mathrm{N}=905)\end{array}$} \\
\hline & & $n(\%)$ & Crude OR $(95 \% \mathrm{Cl})$ & P-value & $n(\%)$ & Crude OR $(95 \% \mathrm{Cl})$ & $P$-value \\
\hline Living in thatched house vs. corrugated sheet & $697(76.8)$ & $322(46.2)$ & $1.62(1.18,2.24)$ & 0.003 & $28(4.0)$ & $0.51(0.27,0.96)$ & 0.037 \\
\hline Toilet use vs. open field§ & $564(62.1)$ & $234(41.5)$ & $0.81(0.62,1.06)$ & 0.080 & $32(5.7)$ & $1.66(0.84,3.26)$ & 0.144 \\
\hline Main water source & & & & 0.188 & & & $<0.001$ \\
\hline Inside pipe ${ }^{\S}$ & $54(6.0)$ & $17(31.5)$ & 1 & & $10(18.5)$ & 1 & \\
\hline Outside pipe ${ }^{\wedge}$ & $577(64.0)$ & $262(45.4)$ & $1.81(1.00,3.29)$ & & $26(4.5)$ & $0.21(0.09,0.46)$ & \\
\hline Well/stream/rain & $118(13.1)$ & $47(39.8)$ & $1.44(0.73,2.85)$ & & $5(4.3)$ & $0.20(0.06,0.61)$ & \\
\hline River & $153(17.0)$ & $66(43.1)$ & $1.65(0.86,3.19)$ & & $3(2.0)$ & $0.09(0.02,0.33)$ & \\
\hline Animal spend the night inside & $573(63.2)$ & $250(43.6)$ & $1.02(0.78,1.34)$ & 0.880 & $22(3.9)$ & $0.57(0.31,1.04)$ & 0.068 \\
\hline Cooking inside the main house & $729(80.8)$ & $334(45.8)$ & $1.68(1.18,2.37)$ & 0.003 & $29(4.0)$ & $0.43(0.23,0.83)$ & 0.012 \\
\hline Soap use & & & & 0.008 & & & 0.299 \\
\hline Daily & $321(35.4)$ & $118(36.8)$ & 1 & $0.003^{\circ}$ & $19(5.9)$ & 1 & $0.576^{\circ}$ \\
\hline At least once a wk & $532(58.6)$ & $249(46.8)$ & $1.51(1.14,2.01)$ & & $21(4.0)$ & $0.65(0.35,1.23)$ & \\
\hline Less frequent than once a week & $55(6.1)$ & $28(50.9)$ & $1.78(1.00,3.17)$ & & $4(7.4)$ & $1.27(0.41,3.88)$ & \\
\hline Household waste disposal $(N=904)$ & & & & 0.013 & & & 0.996 \\
\hline Buried/Burned & $190(21.0)$ & $65(34.2)$ & 1 & & $9(4.8)$ & 1 & \\
\hline Open field & $248(27.3)$ & $115(46.4)$ & $1.66(1.23,2.46)$ & & $12(4.8)$ & $1.02(0.42,2.47)$ & \\
\hline Used as fertilizers & $469(51.7)$ & $215(45.8)$ & $1.63(1.15,2.31)$ & & $23(4.9)$ & $1.04(0.47,2.28)$ & \\
\hline Maternal helminth infection & $395(43.5)$ & - & - & - & $22(5.6)$ & $1.32(0.72,2.42)$ & 0.368 \\
\hline
\end{tabular}

${ }^{\S}$ pit latrine, flush type and improvised pit latrine, ${ }^{\circ} \mathrm{p}$ for trend

$\$$ Inside pipe users are those who have a pipe inside the compound and usually used privately.

${ }^{\wedge}$ Outside pipe users are those whose source of water is from a pipe outside the compound mainly shared.

$\mathrm{N}=$ total number of study participants, $\mathrm{n}=$ number of outcome for each exposure

Table 4 Multivariate analysis of independent risk factors for any soil-transmitted helminth infection in mothers and their children in the Butajira birth cohort, Ethiopia, 2007

\begin{tabular}{|c|c|c|c|c|}
\hline Outcome variable & Risk factor & Adjusted OR & $95 \% \mathrm{Cl}$ & P-value \\
\hline \multirow[t]{10}{*}{ Maternal infection } & Soap use & & & 0.055 \\
\hline & Daily & 1 & & Trend $=0.018$ \\
\hline & At least once a week & 1.40 & $1.04,1.88$ & \\
\hline & Less frequent than once a week & 1.66 & $0.92,2.99$ & \\
\hline & Urban residence* & 0.45 & $0.28,0.73$ & 0.001 \\
\hline & Domestic animals living together & 0.73 & $0.53,1.01$ & 0.055 \\
\hline & Age of the mother* & & & 0.964 \\
\hline & $15-24$ & 1 & & Trend $=0.789$ \\
\hline & $25-34$ & 0.97 & $0.72,1.29$ & \\
\hline & $35-44$ & 0.95 & $0.63,1.44$ & \\
\hline \multirow[t]{7}{*}{ Child infection } & Water source & & & 0.002 \\
\hline & Inside pipe & 1 & & \\
\hline & Outside pipe & 0.21 & $0.09,0.51$ & \\
\hline & Well/stream/rainwater & 0.20 & $0.56,0.69$ & \\
\hline & River & 0.09 & $0.02,0.38$ & \\
\hline & Urban residence* & 1.03 & $0.43,2.45$ & 0.954 \\
\hline & Male gender* & 0.67 & $0.36,1.26$ & 0.216 \\
\hline
\end{tabular}

\footnotetext{
* Place of residence included as a priori confounder, and additionally age of the mother in the mother and gender in the child model
} 
technique was not performed due to issues related to feasibility. However, the results are unique in that they arise from a population based cohort, and provide valuable information on prevalence and risk factors among infants in a low-income setting.

The prevalence of STH infection observed in mothers (43.5\%) was higher than that reported previously (33.8\%) in a random sample of the Butajira Rural Health Project [18]. In this previous study, hookworms were found in $14.7 \%$ of the study population, lower than in our mothers (36.1\%) while $A$. lumbricoides was found in a higher proportion of the general population (16.6\%) than in our mothers $(8.8 \%)$. The low prevalence of hookworm in the previous study may be because the earlier study population was on average younger than the mothers in this study (median age 20 vs. 26 years). Moreover, the previous study consisted of a significantly higher proportion of urban participants, who live in houses with corrugated iron roofs, and were more educated than the birth cohort women. All these factors might explain the lower prevalence of hookworm infection in the earlier study [18].

Multiple STH infections were also less common than in other studies in Ethiopia. Studies in the south and areas around Wondo-Genet report $80 \%$ of populations to be infected with one helminthic parasite, $40 \%$ with two, and 3\% with four $[19,20]$. Such differences might arise from differences in study subjects, socio-demographic conditions of the society or differences in the parasitological examination techniques.

The prevalences of hookworm (2.3\%) and A. lumbricoides $(1.5 \%)$ in our infants were much lower than those found among one year-old children in Jimma, Ethiopia, (hookworm 13.3\%, A. lumbricoides 35.0\%, [21]). The lower prevalence of STHs in children in this population is probably linked to the Enhanced Outreach Strategy (EOS) for child survival, a mass de-worming intervention started in 2006 in under-five children in this area [5]. Even though we were not clearly able to ascertain whether the deworming included our study participants, the intervention might have changed the parental health related behavior or siblings in the household might have received the medication further reducing transmission.

This study showed that maternal hookworm infection was more prevalent (36.1\%) than other STH infection. In their review, Hotez et al indicated that $30 \%$ of Kenyan, $41 \%$ of Nepalese, and $53 \%$ of Vietnamese women of reproductive age had a hookworm infection [2], higher than other STHs and comparable to this study. This may be explained by the fact that women spend more time than men in muddy, wet gardens suitable for third stage infective hookworm larvae. Women in the Butajira area spend much of their time in farm plots and wet gardens covered by false banana, Khat and coffee trees that may all contribute to the survival of hookworm larvae. The higher prevalence of hookworm infection in adulthood may also be explained by the nature of the parasite-host relationship [2]: unlike other soil-transmitted helminths, hookworms secrete many bioactive polypeptides which dampen down host immune responses [2].

The present study also assessed the possible association of STH infection with potential risk factors among mothers and children in the cohort. Several recent studies have identified a range of environmental and social risk factors associated with STH infections [22-24]. However, very few of the environmental and socioeconomic factors were significantly associated in this study; making it comparable to earlier studies in Ethiopia and other less developed countries $[23,25,26]$. One of the factors strongly protecting against maternal helminth infection in this study was daily use of soap by the mothers. It was not the presence of soap in the household but the frequency of its use that protected from STH infection. Several studies have shown a significantly higher prevalence of helminth infection among subjects who rarely washed their hands with soap compared to those who washed their hands regularly [22,25-27].

The other factor protecting mothers from helminth infection was urban residence. This is likely to be related to the lower prevalence of sanitary measures in the rural areas of Ethiopia. For instance, the proportion of the population with access to an improved water source is nearly twice as high in urban as in rural areas [13]. In addition, access to improved sanitation is four times higher in urban than rural areas [13]. Interventions to reduce helminth infection must focus on rural residents. This study also found that using water from a pipe inside a compound was a risk factor for helminth infection in infants. Other studies have shown that helminth infection among pipe users in underdeveloped countries may arise from the poor quality of piped water $[28,29]$. Efforts to minimize microbial contamination of piped water supplies and to monitor water quality are important. However, other unknown factors may contribute to the increased risk associated with piped water and merit further investigation.

\section{Conclusions}

$\mathrm{STH}$ infection is common in mothers in this lowincome birth cohort. Risk factors associated with infection suggest that mass de-worming strategies must also address provision of safe water and health education about soap use, particularly among rural residents.

\section{Acknowledgements}

We thank the technicians of Aklilu Lemma Research Institute of the Medical Parasitology unit for examining the stool samples. We also thank the 
Department of Biology, Addis Ababa University; the Wellcome Trust; Asthma UK; and the UK Association of Physicians for funding the project. We are also grateful to the study participants and the data collectors of Butajira birth cohort.

\section{Author details}

Aklilu Lemma Institute of Pathobiology, Addis Ababa University, Addis Ababa, Ethiopia. ${ }^{2}$ School of Public Health, Addis Ababa University, Addis Ababa, Ethiopia. ${ }^{3}$ Division of Epidemiology \& Public Health, the University of Nottingham, Nottingham, UK. ${ }^{4}$ Department of Psychiatry, Addis Ababa University, Addis Ababa, Ethiopia.

\section{Authors' contributions}

$G D, J B, A V, C H$ \& GM conceived the idea for this study. GM, GD, CH, BE, YB and $A A$ participated in the design and conduct of the study. $Y B$ and $G M$ were responsible for the accuracy of the data. AAm and YB drafted the manuscript. AAm and AV guarantee the statistical analysis. AAm, GD, AV, JB, $Y B$ and $B E$ interpreted the findings. All authors read and approved the final manuscript.

\section{Competing interests}

The authors declare that they have no competing interests.

Received: 4 July 2009

Accepted: 19 January 2010 Published: 19 January 2010

\section{References}

1. Bethony J, Brooker S, Albonico M, Geiger SM, Loukas A, Diemert D, Hotez PJ: Soil-transmitted helminth infections: ascariasis, trichuriasis, and hookworm. The Lancet 2006, 67(9521):1521-1532.

2. Hotez PJ, Brooker S, Bethony JM, Bottazzi ME, Loukas A, Xiao S: Hookworm Infection. N Engl J Med 2004, 351(8):799-807.

3. Hotez JP, de Silva N, Brooker S, Bethony J: Soil-Transmitted Infections: The Nature, Causes and Burden of the Condition. Working paper No.3, Disease Control Priorities Project Bethesda, Maryland: Fogarty International Center, National Institute of Health 2003http://www.dcp2.org/file/19/wp3.pdf.

4. Tadesse Z, Hailemariam A, Kolaczinski JH: Potential for integrated control of neglected tropical diseases in Ethiopia. Trans R Soc Trop Med Hyg 2008, 102(3):213-214.

5. Federal Ministry of Health: Guidelines for the Enhanced Outreach Strategy (EOS) for Child Survival Interventions. Addis Ababa, Ethiopia 2004.

6. WHO: Deworming for health and development. Report of the third global meeting of the partners of parasite control Geneva: World Health Organization 2005

7. Hotez JP, Fenwick A, Savioli L, Molyneux D: Rescuing the bottom billion through control of neglected tropical diseases. The Lancet 2009, 373:1570-75.

8. Brooker S, Hotez PJ, Bunday DAP: Hookworm-Related Anaemia among Pregnant Women: A Systematic Review. PLoS Negl Trop Dis 2008, 2(9): e291.

9. WHO: Control of helminth infections in school-age children. VHS SECAM 2002, 1650.

10. Borkow G, Leng Q, Weisman Z, Stein M, Galai N, Kalinkovicha A, Bentwich Z: Chronic immune activation associated with intestinal helminth infections results in impaired signal transduction and anergy. $J$ Clin Investig 2000, 106(8):1053-1061.

11. Albonico M, Montresor A, Crompton DW, Savioli L: Intervention for the control of soil-transmitted helminthiasis in the community. Adv Parasitol 2006, 61:311-48.

12. Montresor A, Cong DT, Le Anh T, Ehrhardt A, Montadori E, Thi TD, Le Kanhh T, Albonico A, Palmer KL: Cost containment in a school deworming program targeting over 2.7 million children in Vietnam. Trans $R$ Soc Trop Med Hyg 2007, 101:461-1.

13. Central Statistical Agency and ORC Macro: Ethiopian Demographic and Health Survey 2005. Addis Ababa Ethiopia and Calverton, Maryland, USA 2006.

14. Berhane $Y$, Wall $S$, Kebede $D$, Emmelin A, Enquselassie F, Byass $P$, Muhe $L$, Andersson T, Deyessa N, Hogberg U, Gossaye Y, Alem A, Dahlblom K: Establishing an epidemiological field laboratory in rural areas potentials for public health research and interventions. Ethiop $J$ Health Dev 1999, s(13):1-47.
15. Butajira Woreda Health Office: Results of the 10th round mass deworming for Enhanced Outreach Strategy for child survival interventions in 41 Kebeles of Meskan Woreda. A short report 2008.

16. Hanlon C, Medhin G, Alem A, Tesfaye F, Lakew Z, Worku B, Dewey M, Araya M, Abdulahi A, Hughes M, Tomlinson M, Patel V, Prince M: Impact of antenatal common mental disorders upon perinatal outcomes in Ethiopia: the P-MaMiE population-based cohort study. Trop Med Int Health 2009, 14(2):156-66.

17. WHO: Basic laboratory methods in medical parasitology. World Health Organization. Geneva 1991.

18. Davey $G$, Venn A, Belete $H$, Berhane $Y$, Britton J: Wheeze allergic sensitization and geohelminth in Butajira, Ethiopia. Clin Exp Allergy 2005, 35:301-307.

19. Leykun J: Major intestinal helminth infections in the Anuak population of four rural villages in southwestern Ethiopia. Ethiop J Health Sci 2000, 10:1-7.

20. Belay R, Solomon W: Magnitude of Schistosoma mansoni and intestinal helminthic infections among schoolchildren in Wondo-Genet Zuria, Southern Ethiopia. Ethiop J Health Dev 1997, 11(2):125-129.

21. Dagoye D, Bekele Z, Woldemichael K, Nida H, Yimam M, Hall A, Venn A, Britton J, Hubbard R, Lewis S: Wheezing, Allergy, and Parasite Infection in Children in Urban and Rural Ethiopia. Am J Respir Crit Care Med 2003, 167:1369-1373.

22. Curtale F, Pezzotti $P$, Sharbini A, Maadat $H$, Ingrosso $P$, Saad $Y$, Babille $M$ : Knowledge, perceptions and behavior of mothers toward intestinal helminths in Upper Egypt: implications for control. Health Pol Plan 1998, 13:423-432.

23. Curtale F, Pezzotti P, Saad YS, Aloi A: An analysis of individual, household, and environmental risk factors for intestinal helminthic infection among children in Qena governorate, Upper Egypt. J Trop Ped 1999, 45:14-17.

24. Olsen A, Samuelsen H, Onyango-Ouma W: A study of risk factor for intestinal helminth infections using epidemiological and anthropological approaches. J Biosoc Sci 2003, 33:569-584

25. Wordemann M, Polman K, Heredia LTM, Diaz RJ, Madurga AMC, Fernandez FAN, Prado RAC, Espinosa AR, Duran LP, Gorbea MB, Rivero LR, Gryseels B: Prevalence and risk factors of intestinal parasites in Cuban children. Trop Med Int Health 2006, 11:1813-1820.

26. Tadesse $\mathrm{G}$ : The prevalence of intestinal helminthic infections and associated risk factors among school children in Babile town, eastern Ethiopia. Ethiop J Health Dev 2005, 19:140-147.

27. Atukorala TMS, Lanerolle P: Soil-transmitted helminthic infection and its effect on nutritional status of adolescent school girls of low socioeconomic status in Sri Lanka. J Trop Ped 1999, 45:18-22.

28. Carneiro FF, Cifuentes E, Tellez-Rojo MM, Romieu I: The risk of Ascaris lumbricoides infection in children as an environmental health indictor to guide preventive activities in Caparao and Alto Caparao, Brazil. Bull World Health Org 2002, 80:1-10.

29. WHO: Health education in the control of schistosomiasis. Health Geneva 1990, 34:1-2.

\section{Pre-publication history}

The pre-publication history for this paper can be accessed here:http://www. biomedcentral.com/1471-2458/10/21/prepub

doi:10.1186/1471-2458-10-21

Cite this article as: Belyhun et al.: Prevalence and risk factors for soiltransmitted helminth infection in mothers and their infants in Butajira Ethiopia: a population based study. BMC Public Health 2010 10:21. 